\title{
Approaches towards the synthesis of a 2,9,16,23-tetrasubstituted phthalocyanine as a pure isomer
}

\author{
Shafrira Greenberg, A. B. P. Lever, and Clifford C. LeznofF' \\ Department of Chemistry, York University, North York (Toronto), Ont., Canada M3J IP3
}

\begin{abstract}
Shafrira Greenberg, A. B. P. Lever, and Clifford C. Leznoff, Can. J. Chem. 66, 1059 (1988).
Treatment of 4-neopentoxyphthalonitrile with hydrogen sulfide gas yielded 1-imino-6-neopentoxy-3-thioisoindoline and 1-imino-5-neopentoxy-3-thioisoindoline, which on alkylation with iodomethane gave 1-imino-3-methylthio-6-neopentoxyisoindolenine and 1-imino-3-methylthio-5-neopentoxyisoindolenine. The methylthioisoindolenines readily condensed at room temperature to a mixture of tetrasubstituted phthalocyanines and a series of linear open-chained purple compounds characteristic of isoindigos, while condensation at $-20^{\circ} \mathrm{C}$ in the presence of zinc acetate gave, in at least one experiment, 2,9,16,23-tetraneopentoxyphthalocyanine as a pure isomer. The low temperature formation of phthalocyanines is remarkable and the syntheses described herein provide guidelines for the synthesis of pure isomers of 2,9,16,23-tetrasubstituted phthalocyanines. The purple and red compounds are shown to have isoindigo structures rather than a ring-opened phthalocyanine structure as previously reported.
\end{abstract}

Shafrira Greenberg, A. B. P. Lever et Clifford C. Leznoff. Can. J. Chem. 66, 1059 (1988).

La réaction du néopentoxy-4 phtalonitrile et du sulfure d'hydrogène gazeux conduit à l'imino- 1 néopentoxy- 6 thio-3 isoindoline et à l'imino-1 néopentoxy-5 thio-3 isoindoline qui, par alkylation avec l'iodométhane, conduisent à l'imino-1 méthylthio-3 néopentoxy-6 isoindoline et à l'imino-1 méthylthio-3 néopentoxy-5 isoindoline. À la température ambiante, les méthylthioisoindolines se condensent facilement pour donner un mélange de phtalocyanines tétrasubstituées et une série de composés linéaires pourpres caractéristiques des isoindigos; par ailleurs, une condensation à $-20^{\circ} \mathrm{C}$, en présence d'acétate de zinc, a conduit - au moins dans une expérience - à la tétranéopentoxy-2,9,16,23 phtalocyanine sous la forme d'un isomère pur. La formation de phtalocyanines à basse température est remarquable et les synthèses décrites dans ce travail fournissent des indications sur les méthodes de synthèse des isomères purs des phtalocyanines substituées en $2,9,16,23$. On a démontré que les composés pourpre et rouge possèdent des structures reliées à celle de l'isoindigo plutôt que des structures reliées à celle de la phtalocyanine qui avaient été suggérées antérieurement.

Tetrasubstituted phthalocyanines having one substituent on each of the four benzo rings of phthalocyanine have been known for some time (1) but have received more attention recently due to their importance in electrocatalytic studies $(2,3)$. Most tetrasubstituted phthalocyanines are prepared by self-condensation of a suitable 3 or 4-substituted phthalonitrile or derivative $(4,5)$. For example, the isoindoline of 4-neopentoxyphthalonitrile will, upon condensation, give not only 2,9,16,23-tetraneopentoxyphthalocyanine (1) but also the 2,10,16,24-, $2,9,17,24-$, and $2,9,16,24$-tetraneopentoxyphthalocyanine isomers $(6,7)$. Indeed, we have shown that the $2,9,16,23$-tetraneopentoxyphthalocyanine zinc(II) (2) derivative exhibited peaks in its ${ }^{1} \mathrm{H}$ nmr spectrum, indicating the presence of seven of the possible eight environments collectively present in the four isomers (7). A full discussion of this phenomenon was also recently demonstrated for some quaternized tetra-2,3-pyridinoporphyrazines (8). In this latter example, it was suggested that steric considerations favoured the symmetrical isomer, having $C_{4 h}$ symmetry, but that the other isomers were present in lesser amounts. Virtually all tetrasubstituted phthalocyanines known in the literature (1) exist as a mixture of the four possible isomers, and in the case of substituents at the 2 position are usually referred to as the 2,9,16,23-tetrasubstituted isomer. On the other hand, in a very recent paper, Gaspard and Maillard (9) have succeeded in preparing the pure isomer 2,9,17,24-tetratert-butylphthalocyanine zinc(II), using metallic zinc as the condensing agent.

In connection with our studies on multinuclear phthalocyanine $(6,7,10)$ and with the possibility of obtaining one pure isomer of a binuclear phthalocyanine for X-ray diffraction studies, we were interested in exploring synthetic methods of

\footnotetext{
${ }^{1}$ Author to whom correspondence may be addressed.
}

phthalocyanine formation that could give rise exclusively to the $2,9,16,23$-tetrasubstituted phthalocyanines as one isomer. In a previous paper we showed that dithioamides do form phthalocyanines with diiminoisoindolines at modest temperatures (11). We envisioned that a 5-substituted iminothioamide should self-condense in one direction to form exclusively a $2,9,16,23$ tetrasubstituted phthalocyanine as one isomer, because the imino group on one side of the molecule should displace selectively the methythio group on the other side of a second molecule. It turns out that treatment of phthalonitrile (3) with hydrogen sulfide gas gives 1-imino-3-isoindoline (4) directly, as reported by Baguley and Elvidge (12), but 4 does not readily condense to phthalocyanine under normal conditions $(4,5)$. Despite the fact that we were unable to successfully $S$-alkylate dithioamides (11) under a variety of conditions, we found that the iminothioamide 4 is readily alkylated to a separable mixture of $\mathrm{N}$-methyl-2,3-dihydro-3-thioxo- $1 \mathrm{H}$-isoindol-1-one (5) and 1-imino-3-methylthioisoindolenine (6). The $S$-alkyl derivative 6 readily condenses to phthalocyanine (7) under the usual conditions but at room temperature instead of $150^{\circ} \mathrm{C}$ (Scheme 1 ).

This encouraging result led us to examine the possibility of using a substituted 1-imino-3-methylthioisoindolenine in the exclusive formation of 2,9,16,23-tetrasubstituted phthalocyanines as one isomer. Treatment of 4-neopentoxyphthalonitrile (8) with hydrogen sulfide (12) gave a mixture of 1-imino-6neopentoxy-3-thioisoindoline (9) and 1-imino-5-neopentoxy-3thioisoindoline (10), separable by flash chromatography (13). In separate experiments pure 9 and $\mathbf{1 0}$ were treated with iodomethane to give 1-imino-3-methylthio-6-neopentoxyisoindolenine (11) and 1-imino-3-methylthio-5-neopentoxyisoindolenine (12) respectively. In separate experiments, compounds 11 and 12 self-condensed spontaneously at room temperature to 2,9,16,23-tetraneopentoxyphthalocyanine (1), as a mixture 

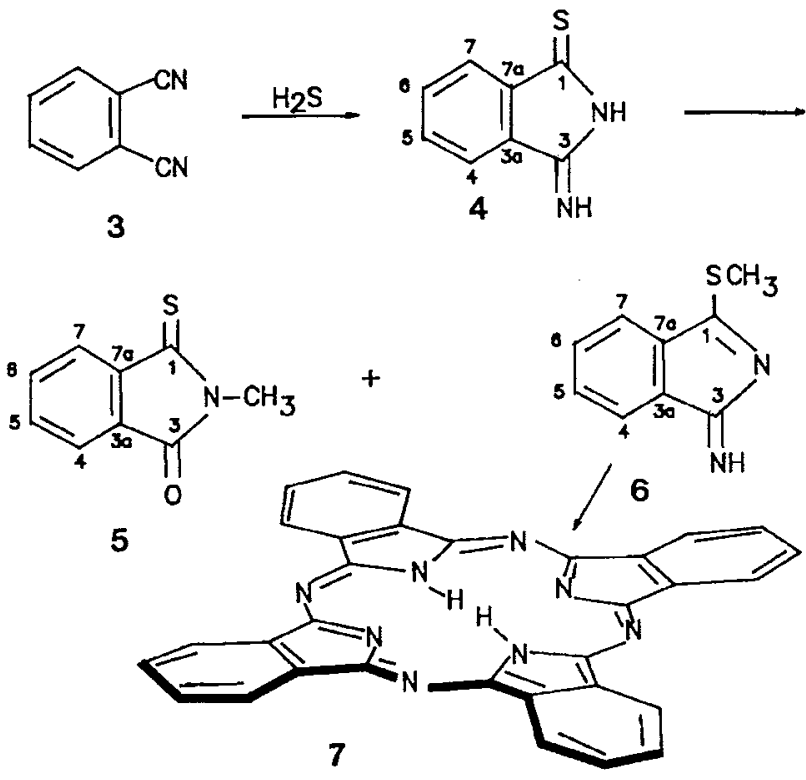

SCHEME 1

of isomers as analyzed previously by ${ }^{1} \mathrm{H} \mathrm{nmr}$ spectroscopy (7). In addition a mixture of purple coloured compounds (13-16) could be recovered by flash chromatography. The assignments of the structures of compounds 13-16 remain tentative and are based on mass spectroscopy, high resolution mass spectroscopy, $\mathrm{nmr}$, and uv/vis spectroscopy. Mass spectroscopy of this mixture of purple compounds could be accounted for by a mixture of compounds (13-16) exhibiting parent ions for all of the compounds. Further purification gave small quantities of pure 13 and 14, whose structures are consistent with their exact high resolution mass spectra (see Experimental). Interestingly, the ${ }^{1} \mathrm{H}$ nmr spectra of 13 and 14 were consistent with the assigned structures but the absorptions for the neopentoxy substituents indicated that 13 and 14 were formed as one isomer each and that mixtures of isomers in which the position of the neopentoxy groups was different in each benzo ring were not obtained. Alternatively, the absorptions of the different positional isomers of 13 and 14 could have been coincident but this possibility is unlikely.

We were interested in characterizing the precursors 4-6 and $9-11$ by ${ }^{13} \mathrm{C} \mathrm{nmr}$ spectroscopy but found that it was necessary to obtain ${ }^{13} \mathrm{C}$ nmr spectra of pure 1,3-diimino-5-neopentoxyisoindoline (17) (see Experimental) and monoiminophthalimide (18) (14) (Fig. 1). Using the ${ }^{13} \mathrm{C} \mathrm{nmr}$ of 17 and 18 it was possible to assign the absorptions of 4-6 and 9-11 (Table 1). In addition, the uv spectra of 4-6, 9-11, and 17 are recorded in Table 2.

It is well known that aromatic thioamides undergo condensation to isoindigo dyes (12), so that the formation of 13-16 is not too surprising. The presence of the neopentoxy substituents of 13-16 solubilized these normally poorly soluble compounds and allowed us to effect a separation to isolate pure $\mathbf{1 3}$ and 14. The uv/vis spectra of 13 and 14 are unique and neither resembles phthalocyanines nor isoindigos. In a recent paper Fujiki et al. (15) describe the preparation of a hydroxygermanium(IV) $\alpha, \beta, \gamma$-triazabenzcorrole formed by a ring contraction of dichlorogermanium phthalocyanine. Illumination of this corrole derivative is reported (15) to give a red compound whose uv/vis is identical to 13 and 14. These authors propose three structures 19-21 for their red compound, none of which would be consistent with the carbon-carbon double bond structure of
13 and 14. In light of our results a possible structure for their red compound could be illustrated below.

A representation of their red compound by the structure 22 in Fig. 2 would be likely and would not involve cleavage of a carbon-carbon double bond. Repetition of the work of Fujiki et al. (15) using neopentoxy-substituted phthalocyanines would give soluble derivatives of their red compound that could be purified and adequately characterized.

Condensation of 11 or 12 at $-20^{\circ} \mathrm{C}$ in dimethylformamide $(\mathrm{DMF})$ and using $\mathrm{Zn}(\mathrm{OAc})_{2}$ as a template for macrocycle formation gave 2 directly and a mixture of purple compounds, likely 13-16. In two experiments, condensation of 11 or 12 led to 2,9,16,23-tetraneopentoxyphthalocyanine 2 as mainly one isomer when examined by ${ }^{1} \mathrm{H} \mathrm{nmr}$ spectroscopy (Table 3), but larger scale preparations of this reaction again led to 2 , but only as a mixture of isomers. Of course, both 2,9,16,23-tetraneopentoxyphthalocyanine (1) and 2,10,16,24-tetraneopentoxyphthalocynanine should exhibit only one peak for the tert-butyl groups and the method of synthesis should favour 1, but the formation of the latter isomer cannot be entirely excluded. It should be pointed out that the mixture of isomers thus obtained was not identical to the statistical distribution of isomers of 2 previously reported (7) (Table 3 ).

In summary, we have demonstrated the remarkable low temperature formation of phthalocyanines from iminomethylthioisoindolenines, have aided in the characterization of the coloured by-products formed in these as similar reactions, and have initiated experiments directed towards the isolation of pure isomers of tetrasubstituted phthalocyanines.

\section{Experimental}

Matheson high purity argon was used to maintain inert atmosphere conditions. Infrared (ir) spectra were recorded on a Pye Unicam SP1000 infrared spectrophotometer using $\mathrm{KBr}$ discs for solids or as neat films between $\mathrm{NaCl}$ discs. Nuclear magnetic resonance ( $\mathrm{nmr}$ ) spectra for carbons and protons were recorded on a Bruker AM300 nmr spectrometer using deuterochloroform as a solvent and tetramethylsilane as the internal standard unless otherwise stated. The positions of the signals are reported in $\delta$ units. (The splittings of the signals are described as singlets (s), doublets (d), triplets $(t)$, quartets $(q)$, or multiplets (m).)

The visible-ultraviolet spectra (uv) were recorded on a Hewlett Packard HP8451A Diode Array spectrophotometer. Mass spectra (ms) were recorded at $70 \mathrm{eV}$ on a VG Micromass $16 \mathrm{~F}$ mass spectrometer in the EI mode.

Melting points (mp) were determined using a Kofler hot stage melting point apparatus and are uncorrected. Thin-layer chromatography (tlc) was performed using silica gel $\mathrm{G}$ as the adsorbent. Flash chromatography was performed using silica gel of particle size 20-45 $\mu \mathrm{m}$. All reactions were stirred with a magnetic stirrer. All solvents were freshly distilled before use. Microanalyses were performed by Guelph Chemical Laboratories Ltd. , Guelph, Ont.

\section{Purification of 5-neopentoxy-1,3-diiminoisoindoline (17)}

The crude 5-neopentoxy-1,3-diiminoisoindoline obtained from 134 $\mathrm{mg}$ of 4-neopentoxyphthalonitrile $(0.63 \mathrm{mmol})$ by standard procedure (6) was dissolved in ethyl acetate, washed with water, and dried over anhydrous magnesium sulfate. Evaporation of the ethyl acetate and recrystallization from ethyl acetate/hexanes gave in $68 \%$ yield $98 \mathrm{mg}$ of pure 5-neopentoxy-1,3-diiminoisoindoline as white crystals, $\mathrm{mp}$ $200-203^{\circ} \mathrm{C}$; ir $\left(\mathrm{cm}^{-1}\right): 3260(\mathrm{NH}), 3200(\mathrm{NH}), 1695,1650$, $1620-1600,1540,1450,1440,1315,1240,1140,1065,1020,885$, $820 ;{ }^{1} \mathrm{H} \mathrm{nmr} \delta: 7.59(\mathrm{~d}, J=8.4,1 \mathrm{H}), 7.24(\mathrm{br}, 1 \mathrm{H}), 7.12(\mathrm{dd}, J=8.4$, $2.1,1 \mathrm{H}), 3.70\left(\mathrm{~s}, 2 \mathrm{H}, \mathrm{CH}_{2} \mathrm{O}\right), 1.06\left(\mathrm{~s}, 9 \mathrm{H},\left(\mathrm{CH}_{3}\right)_{3} \mathrm{C}\right) ; \mathrm{ms} \mathrm{m} / \mathrm{z}: 231$ $\left(\mathrm{M}^{+}, 25\right), 161\left(M^{+}-70,80\right), 71(38), 57(47), 43(100)$. Anal. calcd. for $\mathrm{C}_{13} \mathrm{H}_{17} \mathrm{~N}_{3} \mathrm{O}$ : C 67.51. H 7.41, N 18.17; found: $\mathrm{C} 68.01, \mathrm{H} 7.74, \mathrm{~N}$ 18.05 . 


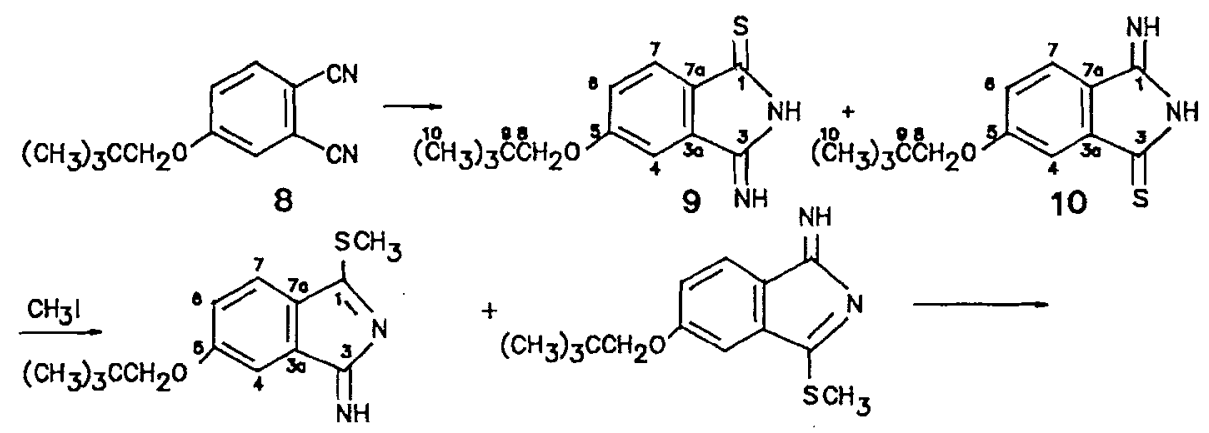

11

12

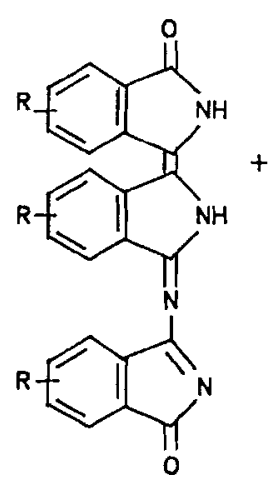

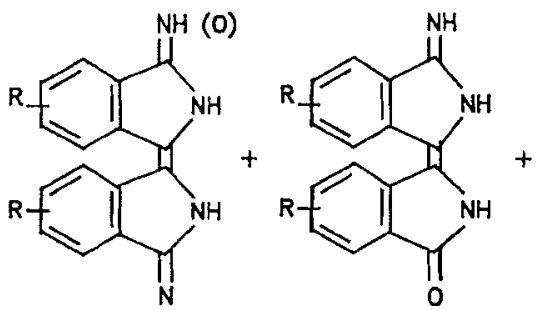<smiles></smiles>

$R F$<smiles>Nc1[nH]cc2ccccc12</smiles><smiles>NC(=O)c1c[R]ccc1C(N)=O</smiles>

$13 \mathrm{R}=\mathrm{OCH}_{2} \mathrm{C}\left(\mathrm{CH}_{3}\right)_{3} \quad 14 \mathrm{R}=\mathrm{OCH}_{2} \mathrm{C}\left(\mathrm{CH}_{3}\right)_{3} \quad 15 \mathrm{R}=\mathrm{OCH}_{2} \mathrm{C}\left(\mathrm{CH}_{3}\right)_{3} \quad 16 \mathrm{R}=\mathrm{OCH}_{2} \mathrm{C}\left(\mathrm{CH}_{3}\right)_{3}$

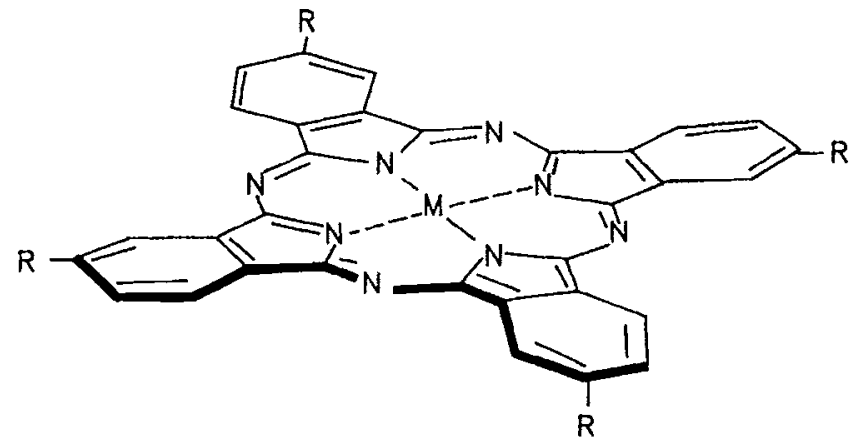

$1 \mathrm{R}=\mathrm{OCH}_{2} \mathrm{C}\left(\mathrm{CH}_{3}\right)_{3}, \mathrm{M}=\mathrm{H}_{2}$

$2 \mathrm{R}=\mathrm{OCH}_{2} \mathrm{C}\left(\mathrm{CH}_{3}\right)_{3}, M=\mathrm{Zn}$

$7 \mathrm{R}=\mathrm{H}, \mathrm{M}=\mathrm{H}_{2}$

SCHEME 2

I-Imino-3-thioisoindoline (4)

The 1-imino-3-thioisoindoline was prepared from phthalonitrile and sodium hydrogen sulfide according to the procedure of Baguley and Elvidge (12), $\mathrm{mp} 220^{\circ} \mathrm{C}$ (dec.) (lit. (12) $\mathrm{mp} 218^{\circ} \mathrm{C}$ ); ir $\left(\mathrm{cm}^{-1}\right.$ ): 3160 (NH), 1665, 1465, 1390, 1290, 1270, 1240, 1080, 910, 765, 675; ' $\mathrm{H}$ nmr (DMSO- $\left.d_{6}\right) \delta$ : 10.88 (vbr. $\left.2 \mathrm{H}, \mathrm{NH}\right), 7.99(\mathrm{~d}, J=7.3,1 \mathrm{H}$ ), $7.81-7.67(\mathrm{~m}, 3 \mathrm{H}) ; \mathrm{ms} \mathrm{m} / \mathrm{z}: 162\left(\mathrm{M}^{+}, 100\right), 146(20), 135(30), 129$ (92), 76 (47).
1-Jmino-3-methylthioisoindolenine (6) and $\mathrm{N}$-methylmonothiophthalimide (5)

A solution of $101 \mathrm{mg}$ of 1 -imino-3-thioisoindoline $(0.63 \mathrm{mmol})$ in 1 $\mathrm{mL}$ ethanol was methylated with dimethyl sulfate according to the procedure of Baguley and Elvidge (12). The crude product was precipitated from water, filtered, and washed with water to give in $65 \%$ yield, $71 \mathrm{mg}$ of 6 . An attempt to recrystallize 6 resulted in decomposition, accompanied by phthalocyanine formation, mp $86-90^{\circ} \mathrm{C}$ (dec.) 
TABLE 1. ${ }^{13} \mathrm{C}$ nuclear magnetic resonance chemical shifts (in ppm ( $\delta$ ), in $\mathrm{CDCl}_{3}$ ) of some imino and thioanalogs of phthalimide

\begin{tabular}{|c|c|c|c|c|c|c|c|c|c|c|c|c|c|}
\hline \multirow[b]{2}{*}{ Compound } & \multicolumn{11}{|c|}{ Carbon } & \multirow[b]{2}{*}{$\mathrm{N}-\mathrm{CH}_{3}$} & \multirow[b]{2}{*}{$\mathrm{S}-\mathrm{CH}_{3}$} \\
\hline & 1 & 3 & $3 a$ & 4 & 5 & 6 & 7 & $7 \mathrm{a}$ & 8 & 9 & 10 & & \\
\hline $4^{a}$ & $199.92^{b}$ & $164.97^{b}$ & 134.00 & 121.72 & $132.54^{c}$ & $132.34^{c}$ & 123.02 & 137.80 & - & - & - & $\ldots$ & - \\
\hline 5 & 197.36 & 169.79 & 127.38 & 123.64 & 134.02 & 133.08 & 122.69 & 137.06 & 一 & - & - & 27.54 & - \\
\hline 6 & 182.37 & 171.52 & 140.45 & 122.75 & $131.12^{c}$ & $130.97^{c}$ & 119.86 & 136.64 & - & - & - & - & 13.25 \\
\hline $9^{a}$ & 197.85 & $163.31^{d}$ & 131.67 & 106.91 & 163.27 & 118.83 & 124.90 & 130.69 & 77.99 & 31.59 & 26.24 & - & - \\
\hline $10^{a}$ & $165.26^{b}$ & $200.23^{b}$ & 140.25 & 107.67 & 162.53 & 118.98 & 123.32 & 122.01 & 77.78 & 31.54 & 26.22 & - & - \\
\hline 11 & n.o. ${ }^{e}$ & n.o. & n.o. & 108.12 & 162.13 & 117.54 & 121.27 & n.o. & 77.83 & 31.58 & 26.24 & - & 12.92 \\
\hline $17^{a}$ & 169.17 & 169.17 & 138.80 & 106.89 & 161.56 & 116.70 & 122.21 & 128.51 & 77.76 & 31.60 & 26.30 & - & - \\
\hline $18^{a \delta}$ & $172.9^{b}$ & $164.5^{b}$ & $134.2^{b}$ & 122.0 & 132.9 & 132.3 & 122.5 & 133.1 & - & - & - & - & - \\
\hline
\end{tabular}

${ }^{a}$ Taken in DMSO- $d_{6}$.

${ }^{b}$ Broadened.

'These values may be interchanged.

${ }^{d}$ Signal overlap with C5.

en.o.: not observed due to low concentration. Sample should not be heated to dissolve.

${ }^{\prime}$ Data taken from ref. 14.<smiles>CC(C)(C)Oc1ccc2c(c1)C(=N)NC2=N</smiles>

17<smiles>N=C1NC(=O)c2ccccc21</smiles>

18

FIG. 1. Compounds used in aiding assignments of ${ }^{13} \mathrm{C} \mathrm{nmr}$ spectra (Table 1).

TABLE 2. Ultraviolet spectra of iminothioisoindolines and related compounds in $\mathrm{CHCl}_{3}$ at $24^{\circ} \mathrm{C}$

\begin{tabular}{cl}
\hline \hline Compound & \multicolumn{1}{c}{$\lambda_{\max }(\mathrm{nm})(\log \epsilon)$} \\
\hline $\mathbf{4}^{a}$ & $234(4.29), 310(4.13), 345(3.90)$ \\
$\mathbf{5}$ & $242(3.75), 300(4.16), 332(4.01)$ \\
$\mathbf{6}^{a}$ & $285(3.98), 436(2.72)$ \\
$\mathbf{9}$ & $258(4.24), 340(4.23)$ \\
$\mathbf{1 0}$ & $256(4.40), 326(4.28)$ \\
$\mathbf{1 1}^{b}$ & $254(4.36), 298(4.18), 366(3.42)$ \\
$\mathbf{1 7}$ & $244(4.24), 266(4.24), 312(\mathrm{sh})(4.12)$ \\
\hline${ }^{a}$ Data taken from ref. 12. \\
${ }^{b}$ This compound is not very stable.
\end{tabular}

(lit. (12) mp 98-100 ${ }^{\circ} \mathrm{C}$; ir $\left(\mathrm{cm}^{-1}\right): 3180(\mathrm{NH}), 1655,1480,1360$, $1265,1240,1040,960,770,760,685 ;{ }^{1} \mathrm{H}$ nmr $\delta: 9.49$ (br, $\left.1 \mathrm{H}\right), 7.93$ (br, $1 \mathrm{H}), 7.55-7.43(\mathrm{~m}, 3 \mathrm{H}), 2.74(\mathrm{~s}, 3 \mathrm{H}, \mathrm{S}-\mathrm{CH}) ; \mathrm{ms} \mathrm{m} / \mathrm{z}: 176$ $\left(\mathrm{M}^{+}, 35\right), 129(100)$.

When left overnight the filtrate deposited orange needles, which were filtered off to give in $9 \%$ yield $10 \mathrm{mg}$ of $N$-methylmonothiophthalimide, mp $97-98^{\circ} \mathrm{C}$ (lit. (16) $\left.\mathrm{mp} 97^{\circ} \mathrm{C}, 86-87^{\circ} \mathrm{C}\right)$; ir $\left(\mathrm{cm}^{-1}\right)$ : $1740(\mathrm{C}=\mathrm{O}), 1470,1375,1340,1325,1075,990,770,700 ;{ }^{1} \mathrm{H} \mathrm{nmr} \delta$ : $7.96(\mathrm{~m}, 1 \mathrm{H}), 7.77(\mathrm{~m}, 1 \mathrm{H}), 7.69(\mathrm{~m}, 2 \mathrm{H}), 3.48\left(\mathrm{~s}, 3 \mathrm{H}, \mathrm{N}-\mathrm{CH}_{3}\right) ; \mathrm{ms}$ $m / z: 177\left(\mathrm{M}^{+}, 100\right), 117(80)$.

1-Imino-6-neopentoxy-3-thioisoindoline (9) and 1-imino-5-neopentoxy-3-thioisoindoline (10)

A suspension of $15.1 \mathrm{~g}$ of sodium sulfide nonahydrate $(62.9 \mathrm{mmol})$ in $5 \mathrm{~mL}$ of water was saturated with a slow stream of hydrogen sulfide gas for $1 \mathrm{~h}$. The suspension became cloudy and the stream of $\mathrm{H}_{2} \mathrm{~S}$ was increased for a further $45 \mathrm{~min}$. The grey solution was then added to a solution of $4.2 \mathrm{~g}$ of 4-neopentoxyphthalonitrile (6) $(19.6 \mathrm{mmol})$ in 11 $\mathrm{mL}$ of $95 \%$ ethanol and the mixture was stirred at room temperature for $48 \mathrm{~h}$. The reaction mixture was diluted with $200 \mathrm{~mL}$ of water and the

precipitate was filtered and washed with water to yield $3.9 \mathrm{~g}$ of crude product. Further purification was done by flash chromatography (13) on silica gel, using ether/petroleum ether (3:2) as eluant. The first 100 mL consisted of dark impurities and a trace of 5-neopentoxydithiophthalimide (11). Continued elution gave a yellow moving band consisting of 1-imino-6-neopentoxy-3-thioisoindoline. Evaporation of the eluant gave in $17 \%$ yield $0.84 \mathrm{~g}$ of pure 9 as very light brown crystals, $\mathrm{mp} 126-130^{\circ} \mathrm{C}$ (dec.); ir $\left(\mathrm{cm}^{-1}\right.$ ): $3280-3180$ (NH), 1660 , $1610,1490,1480-1460,1365,1255,1105,830 ;{ }^{l} \mathrm{H} \mathrm{nmr}$ (acetone- $d_{6}$ ) $\delta: 7.83(\mathrm{~d}, J=8.4,1 \mathrm{H}), 7.53(\mathrm{br}, 1 \mathrm{H}), 7.26(\mathrm{dd}, J=8.4,2.3,1 \mathrm{H})$, $3.82\left(\mathrm{~s}, 2 \mathrm{H}, \mathrm{CH}_{2} \mathrm{O}\right), 1.06\left(\mathrm{~s}, 9 \mathrm{H},\left(\mathrm{CH}_{3}\right)_{3} \mathrm{C}\right) ; \mathrm{ms} \mathrm{m} / \mathrm{z}: 248\left(\mathrm{M}^{+}, 100\right)$, 178 (82), 71 (27), 43 (28). Anal. calcd. for $\mathrm{C}_{13} \mathrm{H}_{16} \mathrm{~N}_{2} \mathrm{OS}$ : C 62.87, $\mathrm{H}$ $6.49, \mathrm{~N} 11.28$; found: C 62.95, H 6.70, N 11.42 .

Continued elution of the silica gel gave a second yellow moving band consisting of 1-imino-5-neopentoxy-3-thioisoindoline. Evaporation of the eluant gave in $20 \%$ yield $0.97 \mathrm{~g}$ of pure 10 as golden crystals, mp $189-191^{\circ} \mathrm{C}\left(\mathrm{dec}\right.$ ); ir $\left(\mathrm{cm}^{-1}\right): 3250(\mathrm{NH}), 1660,1610,1495,1380$, $1365,1325,1280,1200,1050,1020,865,830,820,730 ;{ }^{1} \mathrm{H} \mathrm{nmr}$ (acetone- $\left.d_{6}\right) \delta: 7.88(\mathrm{~d}, J=8.5,1 \mathrm{H}), 7.37(\mathrm{~d}, J=2.2,1 \mathrm{H}), 7.32$ (dd, $J=8.5,2.2,1 \mathrm{H}), 3.83\left(\mathrm{~s}, 2 \mathrm{H}, \mathrm{CH}_{2} \mathrm{O}\right), 1.07\left(\mathrm{~s}, 9 \mathrm{H},\left(\mathrm{CH}_{3}\right)_{3} \mathrm{C}\right) ; \mathrm{ms}$ $m / z: 248\left(\mathrm{M}^{+}, 42\right), 178(80), 71(52), 43(100)$. Anal. calcd. for $\mathrm{C}_{13} \mathrm{H}_{16} \mathrm{~N}_{2} \mathrm{OS}$ : C $62.87, \mathrm{H} 6.49, \mathrm{~N} 11.28$; found: C 63.09, H 6.75, N 11.22 .

1-Imino-3-methylthio-6-neopentoxyisoindolenine (11) and 1-imino-3methylthio-5-neopentoxyisoindolenine (12)

A solution of $64.4 \mathrm{mg}$ of 1-imino-6-neopentoxy-3-thioisoindoline $(0.26 \mathrm{mmol}), 1 \mathrm{~mL}$ ethanol, and $0.22 \mathrm{~mL}$ of $1.25 \mathrm{~N}$ sodium hydroxide $(0.28 \mathrm{mmol}$ ) was diluted with $1 \mathrm{~mL}$ of water and stirred while $0.02 \mathrm{~mL}$ of methyl iodide $(0.32 \mathrm{mmol})$ was added dropwise at room temperature. After 45-60 min, ice-cold water was added and the product was filtered and washed with water to give in $82 \%$ yield $56 \mathrm{mg}$ of 1-imino-3-methylthio-6-neopentoxyisoindolenine as brown crystals. Compound 11 was used directly in the next step, mp $115-117^{\circ} \mathrm{C}$ (turned green); ir $\left(\mathrm{cm}^{-1}\right): 3260-3180(\mathrm{NH}), 1660,1605,1480-1460$, $1360,1250,1100,825 ;{ }^{1} \mathrm{H}$ nmr $\delta: 9.34$ (br, 1H), 7.46 (br, 1H), 7.35 $(\mathrm{d}, J=8.2,1 \mathrm{H}), 7.00(\mathrm{~d}, J=8.2,1 \mathrm{H}), 3.69\left(\mathrm{~s}, 2 \mathrm{H}, \mathrm{CH}_{2} \mathrm{O}\right), 2.72(\mathrm{~s}$, $3 \mathrm{H}, \mathrm{SCH} \mathrm{H}_{3}, 1.05\left(\mathrm{~s}, 9 \mathrm{H},\left(\mathrm{CH}_{3}\right)_{3} \mathrm{C}\right) ; \mathrm{ms} \mathrm{m} / \mathrm{z}: 262\left(\mathrm{M}^{+}, 10\right), 192(23)$, 71 (65), 57 (48), 43 (100). Anal. calcd. for $\mathrm{C}_{14} \mathrm{H}_{18} \mathrm{~N}_{2} \mathrm{OS}: \mathrm{C} 64.09, \mathrm{H}$ 6.92 , N 10.68; found: C 64.06, H. 7.02, N 11.05.

Similarly a solution of $101 \mathrm{mg}$ of 1-imino-5-neopentoxy-3-thioisoindoline was methylated with methyl iodide at $0^{\circ} \mathrm{C}$ for $3 \mathrm{~min}$ to give a dark oily product. The crude product was extracted with ether and the organic layer was washed thoroughly with water. After drying over anhydrous magnesium sulfate, the solvent was evaporated to give in $75 \%$ yield $80 \mathrm{mg}$ of a very dark oil. Compound 12 is very unstable and therefore it is used directly in the next step. An attempt to purify 12 by flash chromatography caused decomposition, hydrolysis of the 


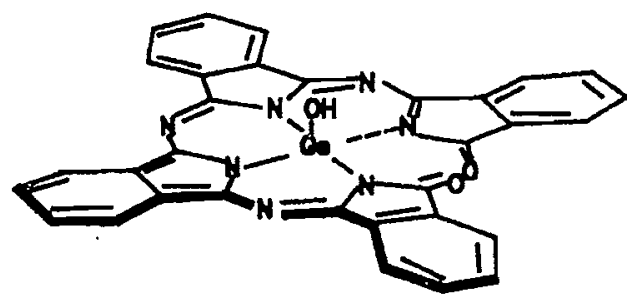

19

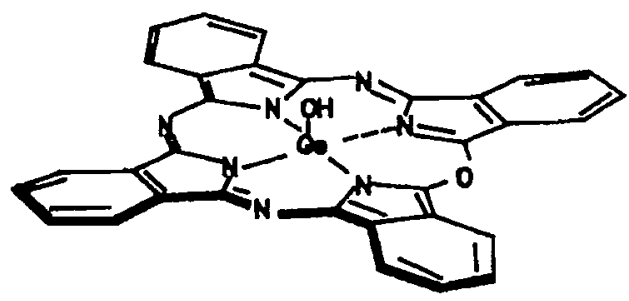

21

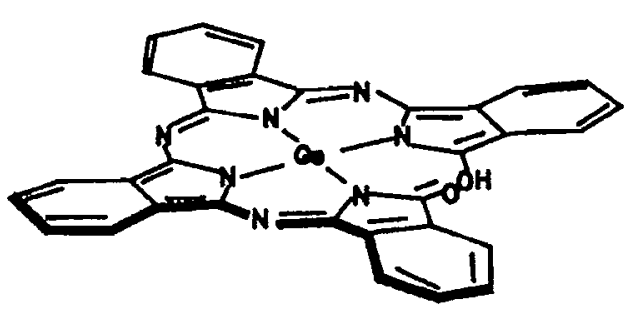

20

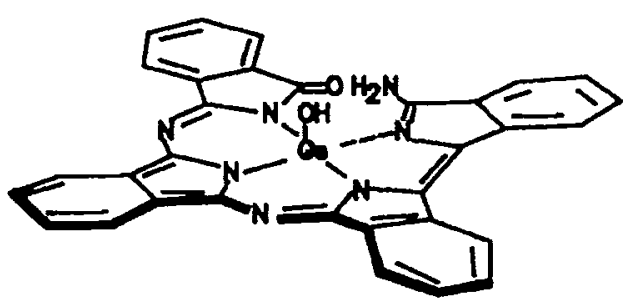

22

Fig. 2. Reported and new suggested structures for the red compound.

TABLE 3. ${ }^{1} \mathrm{H}$ nuclear magnetic resonance chemical shifts (in ppm ( $\delta$ ), of $2,9,16,23$-tetraneopentoxyphthalocyanine (1) and its $\mathrm{Zn}$ derivative (2) for different methods of preparation

\begin{tabular}{|c|c|c|c|c|}
\hline Phthalocyanine & Precursor & $\begin{array}{c}\text { Reaction } \\
\text { conditions }\end{array}$ & $\left(\mathrm{CH}_{3}\right)_{3} \mathrm{C}$ & NH \\
\hline 1 & 17 & $160^{\circ} \mathrm{C}, \mathrm{DMAE}^{a}$ & $1.27,1.26,1.25,1.232,1.226$ & $-4.94,-5.12,-5.21,-5.64$ \\
\hline 1 & 11 & $60^{\circ} \mathrm{C}$, DMAE & $1.29,1.26,1.25,1.24,1.23$ & $-2.62,-4.98,-5.14,-5.27$ \\
\hline 1 & 11 & $24^{\circ} \mathrm{C}, \mathrm{DMAE}$ & $1.28,1.27,1.222,1.218$ & $-2.30,-2.48$ \\
\hline 1 & 12 & $24^{\circ} \mathrm{C}, \mathrm{DMAE}$ & $1.30,1.28,1.27,1.24,1.23$ & $-2.73,-3.27$ \\
\hline 2 & 1 via 17 & $100^{\circ} \mathrm{C}, \mathrm{Zn}(\mathrm{OAc})_{2}$ & $1.27,1.26,1.25,1.22,1.21$ & - \\
\hline 2 & 11 & $-18^{\circ} \mathrm{C}, \mathrm{Zn}(\mathrm{OAc})_{2}$ & $1.26, \quad 1.20$ & - \\
\hline 2 & 12 & $-20^{\circ} \mathrm{C}, \mathrm{Zn}(\mathrm{OAc})_{2}$ & 1.26 & - \\
\hline
\end{tabular}

${ }^{a} N, N$-Dimethylaminoethanol.

imino group, and phthalocyanine formation; ${ }^{1} \mathrm{H} \mathrm{nmr} \delta: 7.64$ (d, $J=9$, $1 \mathrm{H}), 7.44(\mathrm{~d}, J=3,1 \mathrm{H}), 6.97$ (dd, $J=9,3,1 \mathrm{H}), 3.73\left(\mathrm{~s}, 2 \mathrm{H}, \mathrm{CH}_{2} \mathrm{O}\right)$, $2.81\left(\mathrm{~s}, 3 \mathrm{H}, \mathrm{SCH} \mathrm{H}_{3}\right), 1.06\left(\mathrm{~s}, 9 \mathrm{H},\left(\mathrm{CH}_{3}\right)_{3} \mathrm{C}\right) ; \mathrm{ms} \mathrm{m} / \mathrm{z}: 262\left(\mathrm{M}^{+}, 31\right)$, $247\left(M^{+}-15,9\right), 215\left(\mathrm{M}^{+}-\mathrm{SCH}_{3}, 40\right), 192\left(M^{+}-70,14\right), 145$ $(95), 71(98), 43(100)$.

\section{Phthalocyanine formation from 11}

Compound 11 obtained from $100 \mathrm{mg}$ of $9(0.40 \mathrm{mmol})$ in $1-2 \mathrm{~mL}$ of $N, N$-dimethylaminoethanol underwent self-condensation under argon at room temperature for $60 \mathrm{~h}$. The crude reaction product was purified as previously described (6) to give, after flash chromatography, in $5-18 \%$ yield, 2,9,16,23-tetraneopentoxyphthalocyanine (1) as a mixture of isomers. From the ' $\mathrm{H} \mathrm{nmr}$ it seemed that some isomers were more selectively formed than others, but complete selectivity was not obtained. If during the self-condensation the argon is bubbling directly inside the reaction mixture, to remove the ammonia that is formed during the reaction, the desired phthalocyanine is not formed at room temperature. Raising the temperature to $60^{\circ} \mathrm{C}$ (oil bath) increased the yieid but reduced the selectivity of the formation of isomers. Phthalocyanine formation was observed to take place when a solution of $\mathbf{1 1}$ in ether was left at room temperature overnight or when a sample of 11 was left partially dissolved in DMSO- $d_{6}$ inside an nmr tube. In both cases no selectivity towards the formation of one isomer was detected by ${ }^{1} \mathrm{H}$ nmr. During the purification of 1 by flash column chromatography it was observed that some purple material was left on the top of the column. At room temperature the purple colour became very intense. Therefore, after all of 1 was eluted with toluene, the solvent system was changed to 2-methoxyethanol/toluene (1:50). Several fractions were collected and, after evaporation of the solvent, it was found that some fractions contained mixtures of only 13 and 14 . The spectral data of this mixture is given as follows: ir $\left(\mathrm{cm}^{-1}\right): 3400$ (NH) , 2940, 1765, 1730, 1610,1490, 1365, 1230, 1045, 1010, 745; uv (ether): $582,542,510,346 \mathrm{~nm} ;{ }^{1} \mathrm{H} \mathrm{nmr} \delta: 7.75(\mathrm{~d}, J=8.3 \mathrm{~Hz}), 7.32$ (d, $J=2.0 \mathrm{~Hz}$ ), 7.20 (dd, $J=8.2$ and $2.0 \mathrm{~Hz}), 3.71\left(\mathrm{~s}, \mathrm{CH}_{2} \mathrm{O}\right), 1.06$ (s, $\left.\left(\mathrm{CH}_{3}\right)_{3} \mathrm{C}\right) ;{ }^{13} \mathrm{C} \mathrm{nmr} \delta: 168.00,167.93,164.83,135.24,125.18$, $124.27,120.66,108.57,78.80,31.88,29.66,26.44$. Further purification on a few $\mathrm{mg}$ was achieved by preparative tlc using the same eluting solvent as above to give 13 and 14 in estimated yields of $5 \%$ and $7 \%$ respectively; $\mathrm{ms}$ (high resolution) $\mathrm{m} / z$, calcd, for $\mathrm{C}_{39} \mathrm{H}_{44} \mathrm{~N}_{4} \mathrm{O}_{5}, 13$, $\left(\mathrm{M}^{+}\right): 648.35404$; found: 648.3555 ; calcd. for $\mathrm{C}_{52} \mathrm{H}_{61} \mathrm{~N}_{7} \mathrm{O}_{5}, 14,\left(\mathrm{M}^{+}\right)$: 863.47337; found: 863.4696 .

Compounds of related structure were discussed by Fujiki et al. (15). 
Phthalocyanine formation from 12

Compound 12 obtained from $116 \mathrm{mg}$ of $10(0.47 \mathrm{mmol})$ in $1-2 \mathrm{~mL}$ of $N, N$-dimethylaminoethanol underwent self-condensation under argon at room temperature for $18 \mathrm{~h}$. The crude reaction product was purified as previously described (6) to give, after flash chromatography, in $8 \%$ yield, 8 mg of 2,9,16,23-tetraneopentoxyphthalocyanine as a mixture of isomers; some isomers were more selectively formed than others, in comparison with the isomers formed from the selfcondensation of 5-neopentoxy-1,3-diiminoisoindoline $(17)$ at $150^{\circ} \mathrm{C}$. Further elution of the column with 2-methoxyethanol/toluene (1:50) gave purple/red material consisting of 13-16 as analyzed by mass spectroscopy. The physical and spectral data of 1 (except for the ${ }^{1} \mathrm{H}$ $\mathrm{nmr}$ ) were identical to the ones previously reported (6).

2,9,16,23-Tetraneopentoxyphthalocyanine zinc(II) (2)

A mixure of $20 \mathrm{mg}$ of $11(0.076 \mathrm{mmol})$ and $5.7 \mathrm{mg}(0.031 \mathrm{mmol})$ of zinc acetate was cooled in the freezer to $-15^{\circ} \mathrm{C}$. Cold DMF $\left(-15^{\circ} \mathrm{C}\right)$ was added $(1 \mathrm{~mL})$; the mixture turned green and was left in the freezer for 1 week. The crude product was purified by flash column chromatography in a cold room $\left(3^{\circ} \mathrm{C}\right)$. The column was packed a day in advance and was left in the cold room overnight. The crude product was applied to the column as is, and was eluted with cold toluene at $3^{\circ} \mathrm{C}$ to give $1 \mathrm{mg}$ of 2 (5\% yield); ${ }^{1} \mathrm{H} \mathrm{nmr}\left(\mathrm{C}_{6} \mathrm{D}_{6}\right) \delta: 1.26,1.20 ; \mathrm{ms} \mathrm{m} / z: 922\left(\mathrm{M}^{+}, 100\right)$, $851\left(M^{+}-71,40\right), 460\left(M^{+2}-1,65\right)$. Similarly a mixture of 12 derived from $102 \mathrm{mg}$ of 10 (0.41 mmol) underwent self-condensation in the presence of zinc acetate in DMF at $-15--18^{\circ} \mathrm{C}$. Purification as above gave a mixture of 2 contaminated by 13 and 14 . Further purification by preparative tlc using 2 -methoxyethanol/toluene (1:50) as eluting solvent followed by flash column chromatography gave 10.8 mg of 2 in $11 \%$ yield uncontaminated by 13 and $14 ;{ }^{1} \mathrm{H} \mathrm{nmr}\left(\mathrm{C}_{6} \mathrm{D}_{6}\right) 8$ : a major peak at 1.26 and 2 small peaks at 1.23 and $1.21 \mathrm{ppm}$. This experiment was repeated at $-40^{\circ} \mathrm{C}$ and gradually the temperature was raised to $+5^{\circ} \mathrm{C}$. Purification as above gave a trace of the desired product as indicated by a faint blue spot on tlc; ${ }^{1} \mathrm{H} \mathrm{nmr}\left(\mathrm{C}_{6} \mathrm{D}_{6}\right) \delta: 1.26 \mathrm{ppm}$. A control experiment using 11 in 2-N,N-dimethylaminoethanol showed that metal-free phthalocyanine formation did not take place at temperatures below $10^{\circ} \mathrm{C}$.

\section{Acknowledgements}

We are grateful to the Natural Sciences and Engineering Research Council of Canada for financial support of this research. This work was also partially funded by the Office of Naval Research (Washington) and by the Midwest Center for Mass Spectrometry, a National Science Foundation Regional Instrumentation Facility (Grant No. CHE 8211164).
1. F. H. Moser and A. L. Thomas. Phthalocyanine compounds. Van Nostrand - Reinhold, Princeton, NJ. 1963; A. B. P. LEVER. Adv. Inorg. Chem. Radiochem. 7, 27 (1965); F. H. Moser and A. L. Thomas. The phthalocyanines, Vols. I and 2, CRC Press Inc., Boca Raton, FL. 1983.

2. A. B. P. Lever, M. R. Hempstead, C. C. Leznoff, W. Liu, M. Melnik, W. A. Nevin, and P. Seymour. Pure Appl. Chem. 58, 1467 (1986).

3. D. Dolphin, B. R. James, A. J. Murray, and J. R. Thornback. Can. J. Chem. 58, 1125 (1980); B. SIMIC-GLAVASKI, S. ZECEVIC, and E. J. YeAGER. J. Electroanal. Chem. Interfacial Electrochem. 150, 469 (1983); N. Kobayashi and Y. Nishryama. J. Phys. Chem. 89, 1167 (1985); W. A. Nevin, M. R. Hempstead, W. Liu, C. C. Leznoff, and A. B. P. Lever. Inorg. Chem. 26, 570 (1987).

4. P. J. Brach, S. J. Grammatica, O. A. Ossanna, and L. Weinberger. J. Heterocycl. Chem. 7, 1403 (1970).

5. G. PAWLOWSKI and M. HANACK. Synthesis, 287 (1980).

6. C. C. Leznoff, S. M. Marcuccio, S. GreenberG, A. B. P. Lever, and K. B. Tomer. Can. J. Chem. 63, 623 (1985).

7. S. M. Marcuccio, P. I. Svirskaya, S. Greenterg, A. B. P. Lever, C. C. Leznoff, and K. B. Tomer. Can. J. Chem. 63, 3057 (1985).

8. D. Wohrle, J. Gitzel, I. Okura, and S. Aono. J. Chem. Soc. Perkin Trans. 2, 1171 (1985).

9. S. Gaspard and PH. MaIllard. Tetrahedron, 43, 1083. (1987).

10. S. GreenderG, S. M. Marcuccio, C. C. Leznoff, and K. B. Tomer. Synthesis, 406 (1986); W. A. Nevin, W. LiU, S. Greenberg, M. R. Hempstead, S. M. Marcuccio, M. MelNiK, C. C. Leznoff, and A. B. P. Lever. Inorg. Chem. 26, 891 (1987); C. C. LeZnofF, H. LaM, S. M. Marcuccio, W. A. Nevin, P. Janda, N. Kobayashi, and A. B. P. Lever. J. Chem. Soc. Chem. Commun. 699 (1987).

11. C. C. Leznoff, S. Greenderg, B. Khouw, and A. B. P. Lever. Can. J. Chem. 65, 1705 (1987).

12. M. E. Baguley and J. A. Elvidge. J. Chem. Soc. 709 (1957).

13. W. C. Still, M. KaHN, and A. Mitra. J. Org. Chem. 43, 2923 (1978).

14. L. I. Spiessens, and M. J. O. Anteunis. Bull. Soc. Chim. Belg. 92, 965 (1983).

15. M. Fujiki, H. TABEI, and K. ISA. J. Am. Chem. Sac. 108, 1532 (1986).

16. W. Köhler, M. Bubner, and G. Ulbricht. Chem. Ber. 100, 1073 (1967); M. MACHIDA, K. OdA, E. YoshidA, and Y. KanaOKa. J. Org. Chem. 50, 1681 (1985). 